\title{
Exploring sequence space: harnessing chemical and biological diversity towards new peptide leads
}

\author{
Richard Obexer ${ }^{1}$, Louise J Walport ${ }^{1}$, Hiroaki Suga ${ }^{1}$. \\ ${ }^{1}$ Department of Chemistry, Graduate School of Science, The University of Tokyo, 7-3-1 \\ Hongo, Bunkyo-ku, Tokyo 113-0033, Japan \\ *Correspondence: hsuga@chem.s.u-tokyo.ac.jp
}

\begin{abstract}
From their early roots in natural products, peptides now represent an expanding class of novel drugs. Their modular structures make them ideal candidates for pooled library screening approaches. Key technologies for library generation and screening, such as SICLOPPS, phage display and mRNA display, give unparalleled access to tight binding peptides. Through combination with genetic code reprogramming and chemical modifications, access to more natural product-like libraries, spanning non-canonical peptide space, is readily achievable. Recent advances in these fields enable introduction of diverse non-standard motifs, such as cyclisation and backbone methylations. Peptide discovery platforms now allow robust access to potent, highly functionalised peptides against virtually any protein of interest, with typical binding constants in the nanomolar range. Application of these optimised platforms in a drug discovery setting has the potential to significantly accelerate identification of new leads.
\end{abstract}

\section{Introduction}

Secondary metabolites of diverse organisms, including polyketides, alkaloids and peptides, have been a source of inspiration for drug development by chemists for many decades (Figure 1A). For example, penicillins (1), are enzymatically modified tripeptides that represent one of the dominant classes of peptide-based drugs used today. Historically, synthetic exploitation of the chemical space of such naturally occurring peptides has provided a common route to novel therapeutics. To address the global need for new drugs, rather than relying on serendipitous discovery, de novo target-directed lead creation has now become essential.

Peptides represent ideal drug scaffolds due to their simple modular structures that nonetheless can adopt a wide variety of complex topologies. Their size and dense functionalisation make them particularly attractive for "undruggable" targets,[1,2] such as those involving proteinprotein interactions (PPIs). Selective discovery of functionally tailored peptides is, however, experimentally challenging due to the sheer size of their sequence space. To date, rational approaches for tailoring peptide properties have had limited success. Instead, chemists and biologists have developed screening technologies to identify novel peptide leads for targets of therapeutic importance.[3][4]

\section{Peptide discovery strategies}

Conceptually, state-of-the-art peptide discovery strategies all follow the same scheme: 1) creation of a pooled peptide library, 2) isolation of peptides with desired properties, and 3) sequence determination of selected peptides (Figure 2). The increase in throughput was 
enabled by transition from an array format, where the size of the analysed library is limited by reagent quantities and workload, to pooled technologies in which all members are manipulated in parallel. Maintaining a one-to-one link between the peptide sequence and phenotype is the foundation of pooled selection strategies. Recent progress has been significantly enhanced by technical advances in DNA synthesis and sequencing. Taken together the advantages afforded by molecular biology screening techniques have led to their dominance over the past 25 years.

An overview of the most common technologies described in the literature is given in Table 1. Adhering to the principles outlined above, all techniques are somewhat related and share common steps. Requirements during the target selection step can inform the choice of technique. Here we focus on specific examples to highlight unique aspects of these technologies.

\section{Combinatorial chemistry-based screening}

The One-Bead-One-Peptide (1B1P) method, as pioneered by Lam et al. in 1991,[5] is among the oldest examples of pooled screening technologies. Split and pool synthesis techniques were developed to generate diverse libraries of beads, each coated with multiple copies of a unique peptide. Modern protocols allow routine generation of libraries of up to $10^{7}$ compounds, exploiting the whole repertoire of resin-compatible chemistries. Thus diverse backbones, peptoids, $D$-amino acids and peptide cyclisations are readily accessible, giving the largest degree of freedom of all discussed methods. Fluorescent activated cell sorting (FACS) or magnetic bead sorting are now used for positive bead isolation followed by sequence analysis by partial Edman degradation and mass spectrometry (PED-MS) or MS alone.[6,7]

\section{Enhancing diversity through molecular biology}

The challenge for molecular biology selection systems, with their unparalleled library sizes, is generating as chemically creative peptides. To identify macrocylic peptides as potent as naturally occurring ones it is desirable to closely mimic nature by including artificial building blocks and post-translational modifications (PTMs) (Figure 1A).[8] All molecular biology approaches mentioned in this review rely on the ribosome and associated translation machinery. Thus incorporation of non-canonical building blocks is non-trivial, and represents the focus of much current research.

Split-intein circular ligation of peptides and proteins (SICLOPPS) is an in vivo method for discovering head-to-tail cyclised peptides that requires no genetic code reprogramming. Applying amber stop codon suppression, incorporation of unnatural amino acids has been demonstrated.[9] Peptides are typically six amino acids long, including a cysteine residue for splicing.[10] Linkage between geno- and phenotype is achieved through plasmid propagation within cells. The main bottleneck is the achievable library size of $10^{7-9}$, which is limited by transformation efficiency. Unlike most other approaches discussed, this technology allows for functional selection (not only binding) through implementation of a reverse two-hybrid system. Whilst originally implemented in Escherichia coli, SICLOPPS has since been extended to eukaryotic cells, allowing use of more disease-relevant models.[11,12]

Instead of assaying peptides in cellulo, peptides can be displayed on a surface through membrane/envelope protein fusion and manipulated in vitro. The most commonly used 
display technology, phage display, relies on filamentous phages, such as M13.[13] Initial plasmidic libraries are transformed into E. coli for expression, assembly and release of peptide-tagged phages. Subsequently phages are affinity panned to immobilised target protein, and binders are isolated. Enrichment is achieved through iterative selection cycles with reamplified phages. Since this system combines in vivo and in vitro steps, the library size remains limited by transformation efficiency, resulting in a library diversity of $\sim 10^{9}$. Insertion of the in vitro selection step is advantageous, allowing ready combination with other in vitro techniques; peptides can be chemically or enzymatically post-translationally modified increasing chemical diversity and allowing for cyclisation,[14,15] and, most importantly, selection against virtually any protein target is possible.[4]

\section{Approaching maximal diversity through in vitro technologies}

Translation of the libraries in vitro alleviates the need for transformation, increasing the accessible library sizes by five orders of magnitude up to $10^{13-14}$. Without the compartmentalisation provided by a cell, the peptide-nucleic acid linkage must occur concomitant with translation to maintain unambiguous linkage. A prototypic example is mRNA display, where prior to translation, an antibiotic (Puromycin) that normally leads to peptide termination is covalently appended to each RNA strand.[16] Upon peptide translation, Puromycin reacts with the peptide at the stop codon position, resulting in a covalent linkage between peptide and RNA. As for other display technologies affinity panning with immobilised target is the method of choice for identifying binders. To propagate the sequence, RNA is reverse transcribed and the whole procedure is repeated multiple times. Upon enrichment, sequences are elucidated through DNA sequencing.

Reprogramming and "post synthesis modifications" are the primary means of modulating physicochemical properties of peptides, essential for developing peptides with drug-like properties. In particular, peptide backbone modifications, including azolines, $\beta$-amino acids, backbone N-methylation and cyclisation (Figure 3), can lead to increased potency through enhanced structural rigidity, proteolytic stability and cell permeability (c.f. cyclosporine (2)).[17] Recently, through guided sequence optimisation, Wilbs et al. decreased the $\mathrm{K}_{\mathrm{i}}$ of a phage selected peptide 5-fold by a single $\alpha$ - to $\beta$-amino acid substitution.[18] Rather than inclusion through reverse engineering, a priori introduction of artificial amino acids in screening technologies will give rise to new generations of potent peptide drugs.

\section{Alternative routes to diversity: discovery beyond the standard amino acid alphabet}

Traditionally, reprogramming has been done via stop codon suppression or removal of canonical amino acids. More extensive genetic code reprogramming is particularly facile when carrying out in vitro display techniques[19-21] To this end, enhanced library diversity can be achieved through use of a reconstituted translation systems (IVT, e.g. the PURE system) giving compositional freedom e.g. through omission of aminoacyl tRNA synthetases (ARSs). An advantage of the IVT systems is that pre-aminoacylated tRNA can be directly supplied, providing the most direct method for reprogramming. Aminoacylated tRNAs can be chemically synthesised, though this is technically demanding.[22] Instead, artificial amino acids can be charged onto designated tRNAs using natural or modified ARSs.[23] As an alternative to enzymes, Suga created promiscuous aminoacylating ribozymes, so-called flexizymes, which essentially recognise activated carboxylates. Flexizymes thus allow extensive genetic code reprogramming with non-canonical amino acids (Figure 3).[24] Overall the flexible in vitro translation (FIT) method remains the most versatile and least 
labour intensive procedure for genetic code reprogramming in vitro. In tandem with FIT, Iwane et al recently exploited the PURE system to the extreme by removing all 20 ARSs and replacing them with charged tRNAs, elegantly demonstrating that the codon boxes can be split to allow maximum diversity.[25] Using an orthogonal approach, instead of artificially transcribing all tRNAs, Kang and coworkers selectively depleted all E. coli tRNA $^{\text {Arg }}$ with colicin D to divide the arginine codon box.[26] Integrating the FIT system with mRNA display gave rise to the random non-standard peptide integrated discovery (RaPID) system.[27] The versatility of this system is reflected in its broad use in the pharmaceutical industry today.

The translational tolerance of the ribosome has been extensively explored.[17,28-30] Whilst side chain modifications are typically well accepted, backbone modifications present a greater challenge due to the strict contraints of the ribosomal machinery.[31,32] In a comprehensive study Fujino et al demonstrated that 13 different $\beta$-amino acids can be successfully translated in multiple non-consecutive positions within a peptide.[28] Likewise, incorporation of multiple $\mathrm{N}$-alkylated amino acids can be performed using the FIT system.[33] Since 2008 peptide initiation with D-amino acids has been known to be well tolerated, producing largely non-formylated peptides.[34] Moreover, despite the traditional belief that elongation with D-amino acids is highly disfavoured, by use of a variety of precharged D-aminoacyl-tRNAs, increasing numbers of D-amino acids have been translated into internal positions.[29,35] Most recently, Katoh et al demonstrated the ability to incorporate 10 consecutive D-serine residues by use of an optimised translation system in combination with a modified tRNA ${ }^{\text {Glu }}$.[36] In a complementary approach, exploiting enzymes involved in lanthipeptide biosynthesis, Yang et al. post-translationally introduced D-alanine from serine. [37] Enzymatic epimerisation is a phenomenon also seen in PTM of ribosomal peptides as catalysed by PoyD during polytheonamide biosynthesis.[38] Introduction of the PTM enzyme PatD to a modified version of the RaPID system led to cyclodehydration of cysteine, serine and threonine residues to form the corresponding azoline peptides.[39] More recently, the requirements for the downstream regulatory sequence of PatD were revealed to be flexible, allowing production of a wide range of modified peptides with variable C-termini including peptide tags.[40].

More commonly, modifications are introduced chemically. Derda and coworkers have pioneered the use of phage-compatible aldehyde-oxime chemistry to modify aldehydeterminated peptides, for introduction of wide-ranging modifications including sulfonamides, biotin and mannose.[41] They used this chemistry to identify potent chemically-conjugated warhead peptides in functional selections.[42] Similar modifications have been introduced via cysteine disulphide formation and alkylation.[43,44] This chemistry has also proved extremely versatile for peptide cyclisations. Mild alkylation conditions compatible with display technologies are used to create both cyclic and bicyclic libraries, [45-47] and to chemically staple short alpha-helical peptides.[48] Combining this bicycle bridging moiety with the classic $\mathrm{N}$-acetyl chloride cyclisation of the RaPID system, Bashiruddin et al even created tricycles. [49] Alternatives for cyclisations include enzymatic lanthipeptide formation,[50] and crosslinking of two artificial amino acids.[51,52]

\section{Recent applications in drug discovery}

A number of recent examples highlight the success of peptide-based selection techniques for targeting medicinally relevant protein targets. Using the SICLOPPS system, Tavassoli and co-workers identified inhibitors for the HIF-1 $\alpha / \mathrm{HIF}-1 \beta$ PPI $\left(4, K_{\mathrm{D}}=124 \mathrm{nM}\right)$.[53] Using 
phage display, Rebollo et al selected bicyclic inhibitors of Sortase A $\left(\mathbf{5}, K_{\mathrm{D}}=1.5 \mu \mathrm{M}\right)$, the first inhibitor for this target.[54] Through use of the RaPID system Bashiruddin et al elicited a 16 amino acid peptide $\left(6, K_{\mathrm{D}}=3.5 \mathrm{nM}\right)$ against Plexin $\mathrm{B} 1$, a Semaphorin receptor implicated in osteoporosis.[55] Intriguingly the best peptide binds to a crevice distant from the Semaphorin binding site, yet still allosterically inhibits the PPI $\left(\mathrm{IC}_{50}=1.5 \mu \mathrm{M}\right)$ (Figure 1B). Likewise, Jongkees et al. selected a potent nonapeptide inhibitor of human pancreatic $\alpha$ amylase (HPA, 7, $K_{\mathrm{I}}=7 \mathrm{nM}$ ) exhibiting exemplary selectivity over related amylases.[56] The identified peptide has is composed of a small cycle with a long tail that binds to HPA in an unusually compacted conformation (Figure 1B).

\section{Outlook}

Platforms for peptide discovery have matured beyond academia and are now widely adopted by the pharmaceutical industry. Nevertheless new avenues remain to be explored, especially to reduce labour and artifact accumulation. The advent of readily available, affordable nextgeneration sequencing technologies is revolutionising library screening approaches by facilitating early identification of enriching sequences. For example, its application to display has allowed isolation of the best peptides sequences within a single selection round.[57,58] Roberts and co-workers recently developed a method for identifying the binding constants of over 20,000 peptides within their library directly through population sequencing at various time.[59] They identified peptides with picomolar affinities, notably finding that enrichment rank did not directly correlate with binding affinity. In a further innovative use of deep sequencing, Svensen et al recently adapted the Illumina sequencing chip to allow ribosomal peptide synthesis of a DNA library directly as clusters on the chip.[60] By combining this with sequencing of the immobilised DNA library it should soon be possible to combine the large diversity of screening-based methods with the relative speed of array-type systems. The full potential of these technologies is only now beginning to emerge.

The results outlined above have showcased our ability to identify peptides that interact and manipulate a wide-range of medicinally relevant proteins, many of which are challenging to target with small molecules. Peptide leads can act as models for small molecule drug design. Direct applications of peptide therapeutics, especially for intracellular targets, are yet hampered by bioavailability and cell permeability.[61] Whilst advances in genetic code reprogramming and post synthesis peptide modifications have gone some way towards addressing these pharmacokinetic hurdles, a convincing general solution has not yet emerged to address this shortcoming. Efforts towards engineering ever less peptide-like, but nonetheless ribosomally expressed molecules provide an interesting avenue to access unexplored chemical spaces.

\section{Acknowledgments}

This work was supported by the Japan Science and Technology Agency (JST) Core Research for Evolutional Science and Technology (CREST) of Molecular Technologies, the Japan Society for the Promotion of Science (JSPS) Grant-in-Aid Scientific Research (S) (26220204) to H. S. and Grants-in-Aid for JSPS Fellows to R. O. (P15333). This project has received funding from the European Union's Horizon 2020 research and innovation programme under the Marie Skłodowska-Curie grant agreement No 657292 to L. J. W. 


\section{References}

1. Makley LN, Gestwicki JE: Expanding the Number of "Druggable" Targets: NonEnzymes and Protein-Protein Interactions. Chem. Biol. Drug Des. 2013, 81:22-32.

2. Tsomaia N: Peptide therapeutics: Targeting the undruggable space. Eur. J. Med. Chem. 2015, 94:459-470.

3. Galá A, Comor L, Horvati A, Kuleš J, Guillemin N, Mrljak V, Bhide M: Librarybased display technologies: where do we stand? Mol. BioSyst. 2016, 12:2342-2358.

4. Heinis C, Winter G: Encoded libraries of chemically modified peptides. Curr. Opin. Chem. Biol. 2015, 26:89-98.

5. Lam KS, Salmon SE, M. HE, Hruby VJ, Kazmierski WM, Knapp RJ: A new type of synthetic peptide library for identifying ligand-binding activity. Nature 1991, 354:82-84.

6. Semmler A, Weber R, Przybylski M, Wittmann V: De Novo Sequencing of Peptides on Single Resin Beads by MALDI-FTICR Tandem Mass Spectrometry. J. Am. Soc. Mass Spectrom. 2010, 21:215-219.

7. Qian Z, Upadhyaya P, Pei D: Synthesis and Screening of One-Bead-OneCompound Cyclic Peptide Libraries. In Peptide Libraries: Methods and Protocols. Edited by Derda R. Springer New York; 2015:39-53.

8. Goldflam M, Ullman CG: Recent Advances Toward the Discovery of Drug-Like Peptides De novo. Front. Chem. 2015, 3:69.

9. Young TS, Young DD, Ahmad I, Louis JM, Benkovic SJ, Schultz PG: Evolution of cyclic peptide protease inhibitors. Proc. Natl. Acad. Sci. U. S. A. 2011, 108:11052-6.

10. Lennard KR, Tavassoli A: Peptides come round: using SICLOPPS libraries for early stage drug discovery. Chemistry 2014, 20:10608-10614.

11. Kritzer JA, Hamamichi S, McCaffery JM, Santagata S, Naumann TA, Caldwell KA, Caldwell GA, Lindquist S: Rapid selection of cyclic peptides that reduce alphasynuclein toxicity in yeast and animal models. Nat. Chem. Biol. 2009, 5:655-63.

12. Kinsella TM, Ohashi CT, Harder AG, Yam GC, Li W, Peelle B, Pali ES, Bennett MK, Molineaux SM, Anderson DA, et al.: Retrovirally delivered random cyclic Peptide libraries yield inhibitors of interleukin-4 signaling in human B cells. J. Biol. Chem. 2002, 277:37512-8.

13. Krumpe L, Mori T: Potential of phage-displayed peptide library technology to identify functional targeting peptides. Expert Opin. drug Deliv. Opin. drug Deliv. 2007, 2:525.

14. Ng S, Tjhung KF, Paschal BM, Noren CJ, Derda R: Chemical Posttranslational Modification of Phage-Displayed Peptides. In Peptide Libraries: Methods and Protocols. Edited by Derda R. Springer New York; 2015:155-172.

15. Khati M, Pillay TS: Phosphotyrosine phosphoepitopes can be rapidly analyzed by coexpression of a tyrosine kinase in bacteria with a $\mathbf{T} 7$ bacteriophage display library. Anal. Biochem. 2004, 325:164-167.

16. Roberts RW, Szostak JW: RNA-peptide fusions for the in vitro selection of peptides and proteins. Proc. Natl. Acad. Sci. U. S. A. 1997, 94:12297-12302.

17. Rogers JM, Suga H: Discovering functional, non-proteinogenic amino acid containing, peptides using genetic code reprogramming. Org. Biomol. Chem. 2015, 13:9353-9363.

18. Wilbs J, Middendorp SJ, Heinis C: Improving the Binding Affinity of in-VitroEvolved Cyclic Peptides by Inserting Atoms into the Macrocycle Backbone. ChemBioChem 2016, 618:1-6. 
19. Guillen Schlippe Y V., Hartman MCT, Josephson K, Szostak JW: In vitro selection of highly modified cyclic peptides that act as tight binding inhibitors. J. Am. Chem. Soc. 2012, 134:10469-10477.

20. Kawakami $\mathrm{T}$, Murakami $\mathrm{H}$, Suga $\mathrm{H}$ : Ribosomal synthesis of polypeptoids and peptoid-peptide hybrids. $J$. Am. Chem. Soc. 2008, 130:16861-3.

21. Kawakami T, Ishizawa $\mathrm{T}$, Murakami $\mathrm{H}$ : Extensive reprogramming of the genetic code for genetically encoded synthesis of highly $\mathrm{N}$-alkylated polycyclic peptidomimetics. J. Am. Chem. Soc. 2013, 135:12297-12304.

22. Hecht SM, Alford BL, Kuroda Y, Kitano S: “Chemical Aminoacylation” of tRNA's. J Biol Chem 1978, 253:4517-4520.

23. Young TS, Schultz PG: Beyond the canonical 20 amino acids: Expanding the genetic lexicon. J. Biol. Chem. 2010, 285:11039-11044.

24. Morimoto J, Hayashi Y, Iwasaki K, Suga H: Flexizymes: Their evolutionary history and the origin of catalytic function. Acc. Chem. Res. 2011, 44:1359-1368.

25. Iwane Y, Hitomi A, Murakami H, Katoh T, Goto Y, Suga H: Expanding the amino acid repertoire of ribosomal polypeptide synthesis via the artificial division of codon boxes. Nat Chem 2016, advance on:1-9.

26. Lee KB, Hou CY, Kim CE, Kim DM, Suga H, Kang TJ: Genetic Code Expansion by Degeneracy Reprogramming of Arginyl Codons. ChemBioChem 2016, 33:11981201.

27. Hipolito CJ, Suga H: Ribosomal production and in vitro selection of natural product-like peptidomimetics: the FIT and RaPID systems. Curr. Opin. Chem. Biol. 2012, 16:196-203.

28. Fujino T, Goto Y, Suga H, Murakami H: Ribosomal Synthesis of Peptides with Multiple ß-Amino Acids. J. Am. Chem. Soc. 2016, 138:1962-1969.

29. Fujino T, Goto Y, Suga H, Murakami H: Reevaluation of the d-amino acid compatibility with the elongation event in translation. J. Am. Chem. Soc. 2013, 135:1830-1837.

30. Goto Y, Ohta A, Sako Y, Yamagishi Y, Murakami H, Suga H: Reprogramming the translation initiation for the synthesis of physiologically stable cyclic peptides. ACS Chem. Biol. 2008, 3:120-9.

31. Pavlov MY, Watts RE, Tan Z, Cornish VW, Ehrenberg M, Forster AC: Slow peptide bond formation by proline and other $\mathbf{N}$-alkylamino acids in translation. Proc. Natl. Acad. Sci. U. S. A. 2009, 106:50-4.

32. Englander MT, Avins JL, Fleisher RC, Liu B, Effraim PR, Wang J, Schulten K, Leyh TS, Gonzalez RL, Cornish VW: The ribosome can discriminate the chirality of amino acids within its peptidyl-transferase center. Proc. Natl. Acad. Sci. U. S. A. 2015, 112:6038-6043.

33. Kawakami T, Murakami H, Suga H: Messenger RNA-Programmed Incorporation of Multiple N-Methyl-Amino Acids into Linear and Cyclic Peptides. Chem. Biol. 2008, 15:32-42.

34. Goto $\mathrm{Y}$, Murakami $\mathrm{H}$, Suga $\mathrm{H}$ : Initiating translation with D-amino acids. $R N A$ 2008, 14:1390-8.

35. Achenbach J, Jahnz M, Bethge L, Paal K, Jung M, Schuster M, Albrecht R, Jarosch F, Nierhaus KH, Klussmann S: Outwitting EF-Tu and the ribosome: Translation with D-amino acids. Nucleic Acids Res. 2015, 43:5687-5698.

36. Katoh T, Tajima K, Suga H: Consecutive Elongation of D-Amino Acids in Translation. Cell Chem. Biol. 2016, doi:10.1016/j.chembiol.2016.11.012.

37. Yang X, Van Der Donk WA: Post-translational Introduction of d -Alanine into Ribosomally Synthesized Peptides by the Dehydroalanine Reductase NpnJ. J. Am. 
Chem. Soc. 2015, 137:12426-12429.

38. Freeman MF, Helf MJ, Bhushan A, Morinaka BI, Piel J: Seven enzymes create extraordinary molecular complexity in an uncultivated bacterium. Nat. Chem. 2016, doi:10.1038/NCHEM.2666.

39. Goto Y, Ito Y, Kato Y, Tsunoda S, Suga H: One-pot synthesis of azoline-containing peptides in a cell-free translation system integrated with a posttranslational cyclodehydratase. Chem. Biol. 2014, 21:766-774.

40. Goto Y, Suga H: A Post-translational Cyclodehydratase, PatD, Tolerates Sequence Variation in the C-terminal Region of Substrate Peptides. Chem. Lett. 2016, 45:1247-1249.

41. Kitov PI, Vinals DF, Ng S, Tjhung KF, Derda R: Rapid, hydrolytically stable modification of aldehyde-terminated proteins and phage libraries. $J$. Am. Chem. Soc. 2014, 136:8149-8152.

42. Tjhung KF, Kitov PI, Ng S, Kitova EN, Deng L, Klassen JS, Derda R: Silent Encoding of Chemical Post-Translational Modifications in Phage-Displayed Libraries. J. Am. Chem. Soc. 2016, 138:32-35.

43. Arai $\mathrm{K}$, Tsutsumi $\mathrm{H}$, Mihara $\mathrm{H}$ : A monosaccharide-modified peptide phage library for screening of ligands to carbohydrate-binding proteins. Bioorganic Med. Chem. Lett. 2013, 23:4940-4943.

44. Li S, Roberts RW: A Novel Strategy for In Vitro Selection of Peptide-Drug Conjugates. Chem. Biol. 2003, 10:233-239.

45. Jafari MR, Deng L, Kitov PI, Ng S, Matochko WL, Tjhung KF, Zeberoff A, Elias A, Klassen JS, Derda R: Discovery of light-responsive ligands through screening of a light-responsive genetically encoded library. ACS Chem. Biol. 2014, 9:443-450.

46. Heinis C, Rutherford T, Freund S, Winter G: Phage-encoded combinatorial chemical libraries based on bicyclic peptides. Nat. Chem. Biol. 2009, 5:502-507.

47. Timmerman P, Beld J, Puijk WC, Meloen RH: Rapid and quantitative cyclization of multiple peptide loops onto synthetic scaffolds for structural mimicry of protein surfaces. ChemBioChem 2005, 6:821-824.

48. Diderich P, Bertoldo D, Dessen P, Khan MM, Pizzitola I, Held W, Huelsken J, Heinis C: Phage Selection of Chemically Stabilized $\alpha$-Helical Peptide Ligands. ACS Chem. Biol. 2016, 11:1422-1427.

49. Bashiruddin NK, Nagano M, Suga H: Synthesis of fused tricyclic peptides using a reprogrammed translation system and chemical modification. Bioorg. Chem. 2015, 61:45-50.

50. Bosma T, Kuipers A, Bulten E, de Vries L, Rink R, Moll GN: Bacterial display and screening of posttranslationally thioether-stabilized peptides. Appl. Environ. Microbiol. 2011, 77:6794-6801.

51. Yamagishi Y, Ashigai H, Goto Y, Murakami H, Suga H: Ribosomal synthesis of cyclic peptides with a fluorogenic oxidative coupling reaction. Chembiochem 2009, 10:1469-72.

52. Sako Y, Morimoto J, Murakami H, Suga H: Ribosomal synthesis of bicyclic peptides via two orthogonal inter-side-chain reactions. J. Am. Chem. Soc. 2008, 130:72327234.

53. Miranda E, Nordgren IK, Male AL, Lawrence CE, Hoakwie F, Cuda F, Court W, Fox KR, Townsend PA, Packham GK, et al.: A cyclic peptide inhibitor of HIF-1 heterodimerization that inhibits hypoxia signaling in cancer cells. $\mathrm{J}$. Am. Chem. Soc. 2013, 135:10418-25.

54. Rentero Rebollo I, McCallin S, Bertoldo D, Entenza JM, Moreillon P, Heinis C: Development of Potent and Selective S. aureus Sortase A Inhibitors Based on 
Peptide Macrocycles. ACS Med. Chem. Lett. 2016, 7:606-611.

55. Matsunaga Y, Bashiruddin NK, Kitago Y, Takagi J, Suga H: Allosteric Inhibition of a Semaphorin 4D Receptor Plexin B1 by a High-Affinity Macrocyclic Peptide. Cell Chem. Biol. 2016, 23:1341-1350.

56. Jongkees S a. K, Caner S, Tysoe C, Brayer GD, Withers SG, Suga H: Rapid discovery of potent and selective glycosidase-inhibiting de novo peptides. Cell Chem. Biol. 2017, [no volume].

57. T'Hoen PAC, Jirka SMG, Ten Broeke BR, Schultes EA, Aguilera B, Pang KH, Heemskerk H, Aartsma-Rus A, Van Ommen GJ, Den Dunnen JT: Phage display screening without repetitious selection rounds. Anal. Biochem. 2012, 421:622-631.

58. Olson CA, Nie J, Diep J, Al-Shyoukh I, Takahashi TT, Al-Mawsawi LQ, Bolin JM, Elwell AL, Swanson S, Stewart R, et al.: Single-round, multiplexed antibody mimetic design through mRNA display. Angew. Chemie - Int. Ed. 2012, 51:1244912453.

59. Jalali-Yazdi F, Huong lai L, Takahashi TT, Roberts RW: High-Throughput Measurement of Binding Kinetics by mRNA Display and Next-Generation Sequencing. Angew. Chemie - Int. Ed. 2016, 55:4007-4010.

60. Svensen N, Peersen OB, Jaffrey SR: Peptide Synthesis on a Next-Generation DNA Sequencing Platform. ChemBioChem 2016, doi:10.1002/cbic.201600298.

61. Furukawa A, Townsend CE, Schwochert JA, Pye CR, Bednarek MA, Lokey RS: Passive membrane permeability in cyclic peptomer scaffolds is robust to extensive variation in side chain functionality and backbone geometry. J. Med. Chem. 2016, doi:10.1021/acs.jmedchem.6b01246.

62. Cull MG, Miller JF, Schatz PJ: Screening for receptor ligands using large libraries of peptides linked to the $\mathbf{C}$ terminus of the lac repressor. Proc. Natl. Acad. Sci. U. S. A. 1992, 89:1865-1869.

63. Hansson M, Samuelson P, Gunneriusso E, Stahl S: Surface Display on Gram Positive Bacteria. Comb. Chem. High Throughput Screen. 2001, 4:171-184.

64. Boder ET, Wittrup KD: Yeast surface display for screening combinatorial polypeptide libraries. Nat. Biotechnol. 1997, 15:553-557.

65. Smith GP: Filamentous fusion phage: novel expression vectors that display cloned antigens on the virion surface. Science 1985, 228:1315-1317.

66. Odegrip R, Coomber D, Eldridge B, Hederer R, Kuhlman PA, Ullman C, FitzGerald $\mathrm{K}$, McGregor D: CIS display: In vitro selection of peptides from libraries of protein-DNA complexes. Proc. Natl. Acad. Sci. U. S. A. 2004, 101:2806-10.

67. Mattheakis LC, Bhattt RR, Dower WJ: An in vitro polysome display system for identifying ligands from very large peptide libraries. Biochemistry 1994, 91:90229026.

68. Yamagishi Y, Shoji I, Miyagawa S, Kawakami T, Katoh T, Goto Y, Suga H: Natural Product-Like Macrocyclic N -Methyl-Peptide Inhibitors against a Ubiquitin Ligase Uncovered from a Ribosome-Expressed De Novo Library. Chem. Biol. 2011, 18:1562-1570.

69. Ishizawa T, Kawakami T, Reid PC, Murakami H: TRAP display: A high-speed selection method for the generation of functional polypeptides. $J$. Am. Chem. Soc. 2013, 135:5433-5440.

25) ** Through construction of a PURE-based artificial translation system with all native ARSs omitted the authors demonstrate the potential to significantly expand the genetic code by introduction of all desired pre-amino-acylated tRNAs. 
26) * The authors artificially divide the arginine codon box by removal of native arginine tRNAs using Colicin D and reintroduction of individually pre-charged arginine tRNAs.

28) ** The authors singly introduce 13 different $\beta$-amino acids into a peptide chain, providing the first example of such wildtype ribosomal incorporation.

36) ** Incorporation of up to 10 consecutive D-amino acids was achieved through use of an engineered tRNA ${ }^{\text {Glu }}$ and translation system (increased EF-Tu/Ts, IF2 and decreased EF-G).

56) * The authors use the RaPID system to identify a potent nonapeptide inhibitor of human pancreatic $\alpha$-amylase with high selectivity over other glycosidases

$59) * *$ By use of HTS combined with mRNA display, the authors directly measure the $\mathrm{K}_{\mathrm{D}}$ of selected peptides in addition to the rank order by enrichment level. Their method allowed them to identify higher affinity, but less enriched peptides that would not have been identified by traditional screening methods.

$37) *$ The authors show the assymetric reduction of dehydroalanine, generated from serine, using NpnJ reductase and NADPH. Their reconstituted in vitro system shows a broad substrate tolerance.

38) * Polytheonamide is a ribosomal peptide, with up to 50 site specific post-translational modifications including epimerization and methylation. Here, the authors show that only seven enzymes are sufficient for generating the final peptide.

39) * The authors have established a "one-pot" procedure for generating azoline containing peptides in vitro by combining the FIT system with the posttranslational cyclodehydratase PatD.

55) * The authors show the generation and characterisation of a macrocyclic peptide, which allosterically inhibits Semaphorin receptor Plexin B1.

60) ** On an Illumina sequencing chip, DNA clusters were transcribed into RNA and translated into peptides, both being immobilised to the original DNA cluster. This platform sets the stage for massive parallel peptide screening.

Figure 1 Examples of natural and selected peptides. (A) Examples of natural macrocyclic peptides include penicillins (1), Cyclosporin A (2) or $\alpha$-Amanitin (3). N-methylations are highlighted in pink, non-canonical side chains are indicated in green, cyclisations are emphasised in blue and D-amino acids are indicated with an orange star. (B) Cyclic peptides selected against various protein targets using peptide discovery platforms. Blue backgrounds indicate the peptide backbone and yellow highlights indicate cysteine alkylations for cyclisation. Cyclo-CLLFVY (4) disrupts the HIF-1 $\alpha / \mathrm{HIF}-1 \beta$ PPI and was identified using SICLOPPS.[53] Compound $\mathbf{5}$ is a sortase A inhibitor and was identified using phage dispay.[54] PB1m6 (6) is an allosteric inhibitor of the PPI between Semaphorin and Plexin $\mathrm{B} 1$ and was discovered using the RaPID platform. The co-crystal structure of Plexin B1 (grey) and PB1m6 (cyan) and a close up view thereof is shown below (PDB ID: 5B4W), indicating that the peptide-binding site is distant from the PPI surface. The peptide itself adopts a $\beta$-sheet like structure. Dashed yellow lines indicate intra and inter-molecular polar contacts.[55] Peptide piHA-Dm (7) against HPA was identified through the RaPID system. 
The co-crystal structure (PDB ID: 5KEZ) of the peptide (cyan)) and HPA (grey) shows an unusually compact conformation of the peptide.

Figure 2 Overview of the main screening technologies used for cyclic peptide discovery. (A) All procedures require initial library generation (green background). In the case of the 1B1P method peptide libraries are synthesised directly on the beads by split-and-pool chemistry. Beads are divided and subjected to a single peptide coupling step, then repooled. This procedure is iterated until peptides of the desired length are achieved. In all other methods library diversity is created by DNA synthesis and subsequent transcription and translation. For SICLOPPS the DNA library is transformed into cells as plasmids. The expressed pre-peptides undergo self-splicing, yielding the final cyclic peptides. In phage display the DNA library is transformed into bacteria as plasmids to allow phage expression, assembly, with individual members of the peptide library expressed on their surface, and subsequent release. In mRNA display the DNA library is transcribed and translated using an in vitro translation system. Each mRNA molecule is covalently linked to its encoded peptide by puromycin during translation. This procedure can be combined with the FIT system to give the RaPID system. In the FIT system ribozymes known as flexizymes are used to charge tRNA with any unnatural amino acids of choice. (B) Following library synthesis, sequences with desired properties are isolated (pink background). For 1B1P approaches, peptide bearing beads are incubated with e.g. fluorescently labeled target for FACS. In the SICLOPPS system peptides are selected using a functional assay. Peptides are fused to a transcription factor allowing implementation of a reverse bacterial 2-hybrid system. If peptides disrupt the desired PPI cells survive. In all other cases the cells die. In vitro technologies (e.g. phage display and RaPID) peptides are selected by affinity panning with bead-immobilised target. The recovered sequences serve as input for repetition of the selection process to strongly enrich binding sequences. (C) Finally, sequences of isolated/enriched peptides are determined (blue background). For 1B1P positive clones analysed by MS. For molecular biology based methods top hits are identified by DNA sequencing, either through standard Sanger sequencing or high throughput sequencing.

Figure 3 Examples of non-canonical amino acids and chemistries accessible by genetic code reprogramming or post-translational modifications. (A-D) A selection of nonnatural amino acids that can be incorporated using the FIT system (E) Cyclisation methods using one (top) or multiple (middle, lower) non-natural amino acids.

Table 1 - Summary of key features of screening technologies commonly used for cyclic peptide discovery 
A<smiles>CC1(C)C(=O)C(NC(=O)O)NC1C(=O)O</smiles>

Penicillin (1)
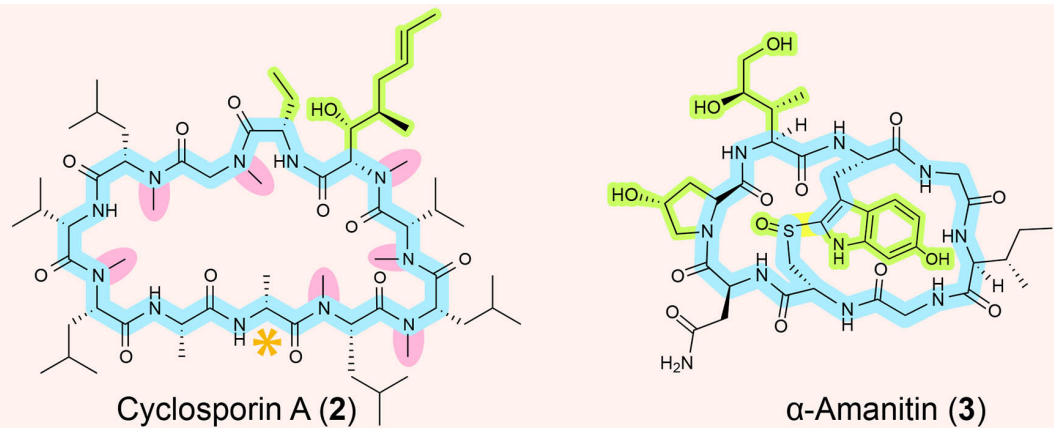

B

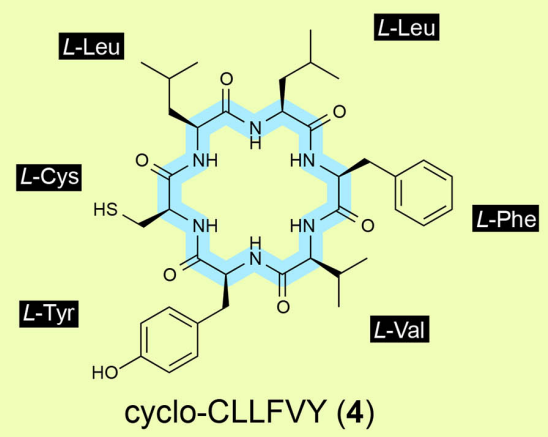

L-Thr L-Trp
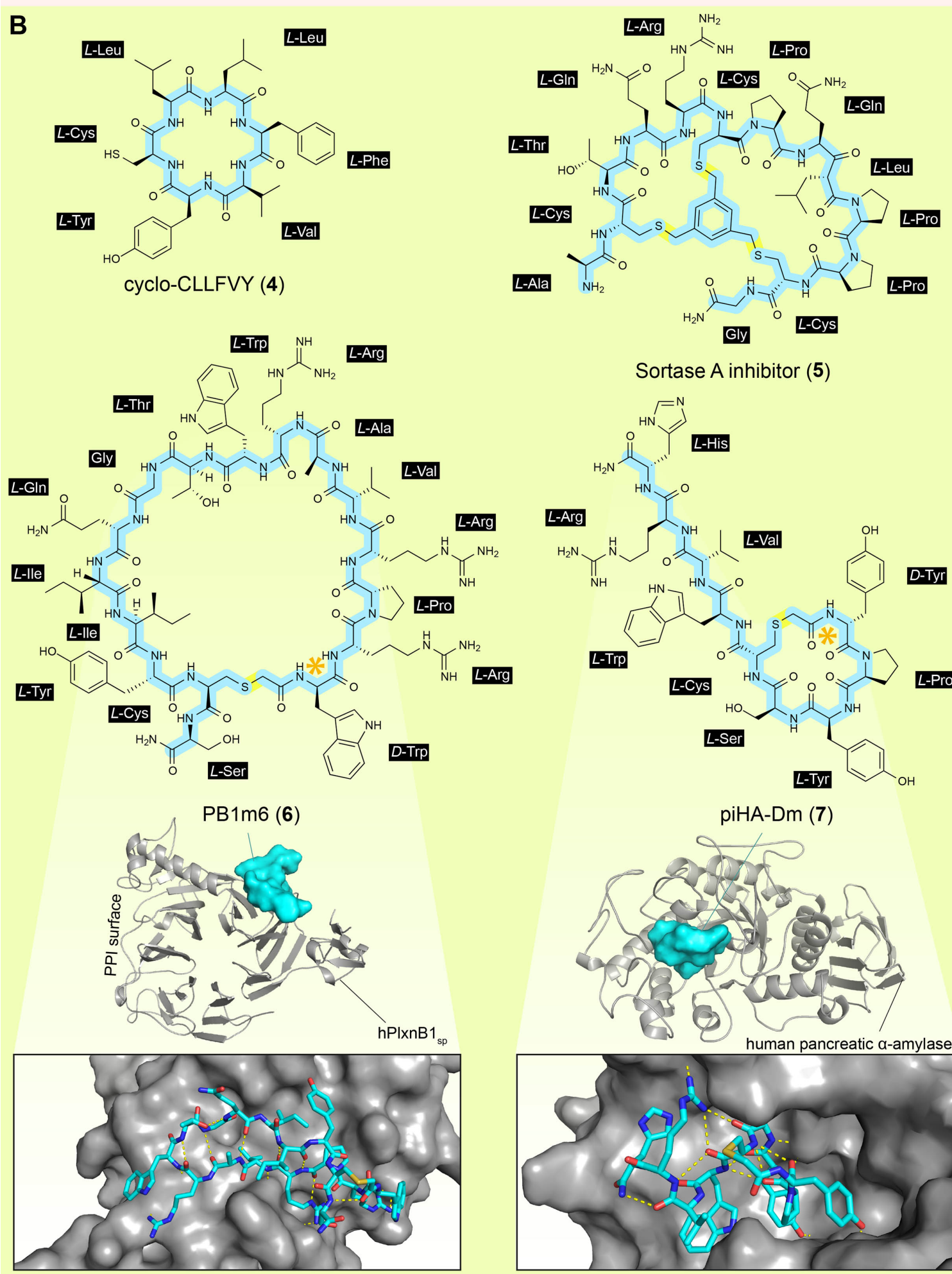

a-Amanitin (3)

Sortase A inhibitor (5)
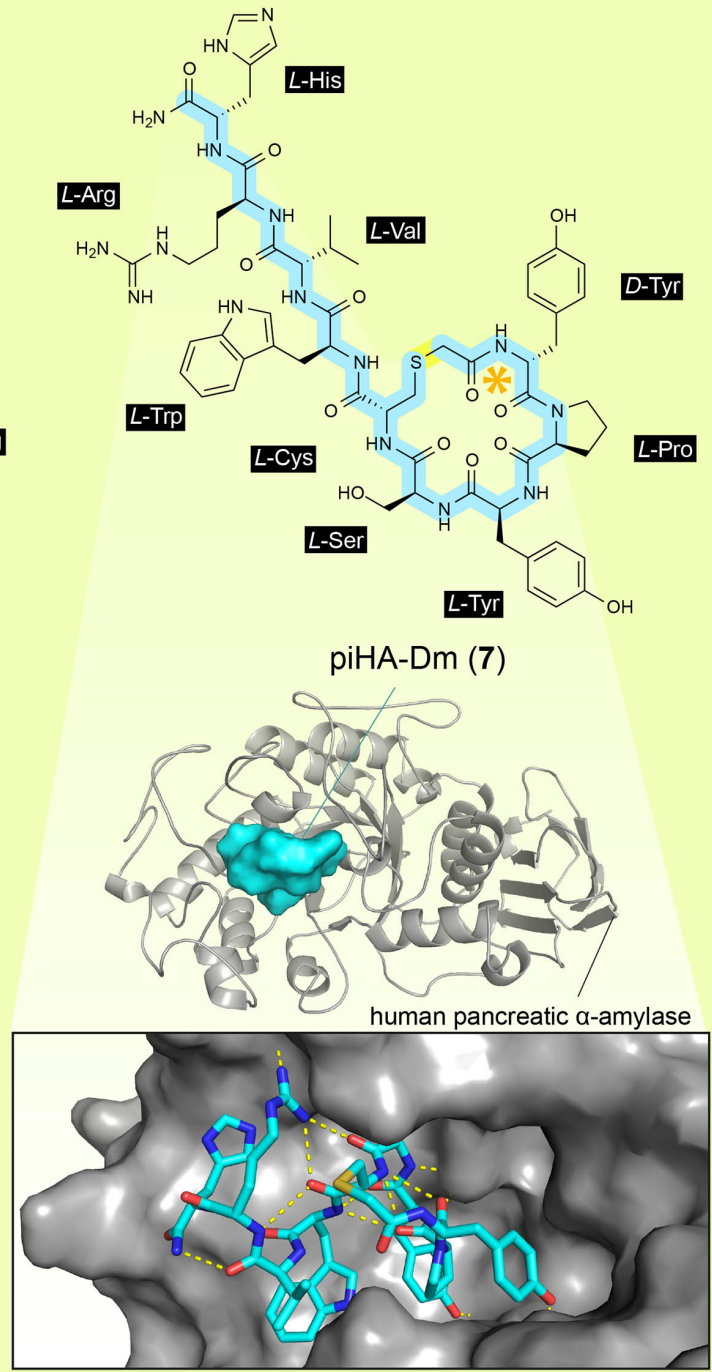


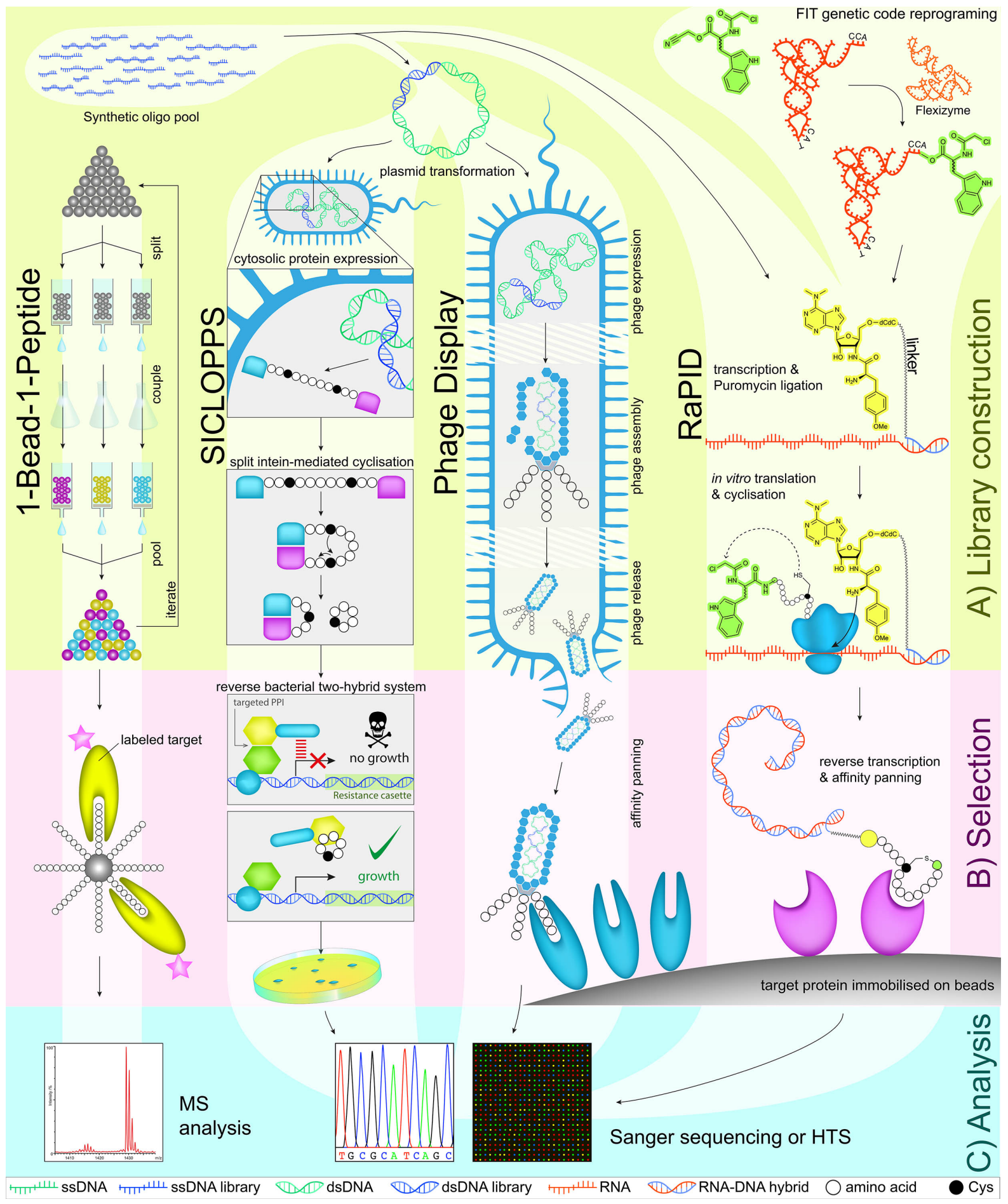



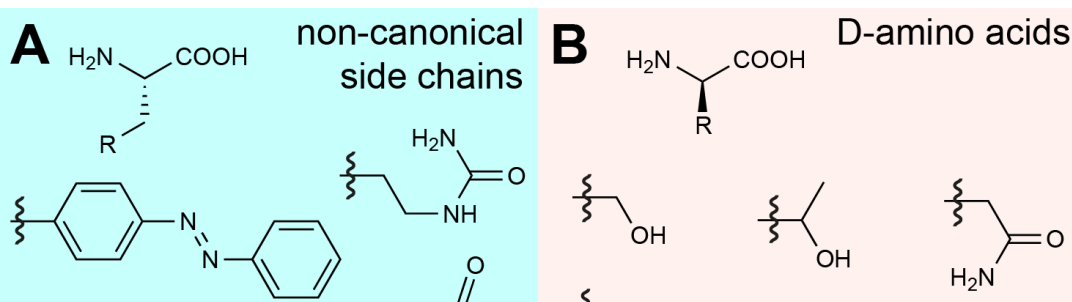<smiles>CC(C)(C)c1ccc(NC(=O)CCCCC2SCC3NC(=O)NC32)cc1</smiles><smiles>CCCc1ccccc1</smiles>
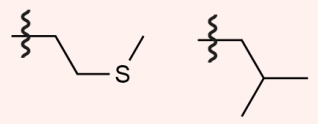

C

$\mathrm{N}$-methyl amino acids

D<smiles>[R]C[C@@H](NC)C(=O)O</smiles><smiles>CCCCCC(C)C(N)=O</smiles><smiles>Cc1c[nH]c2ccccc12</smiles><smiles>CCCSC</smiles><smiles>CCC(N)=O</smiles><smiles>CCCC(=O)O</smiles>
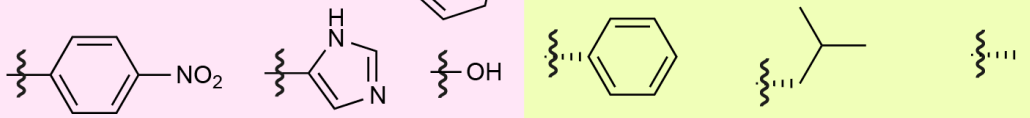

E
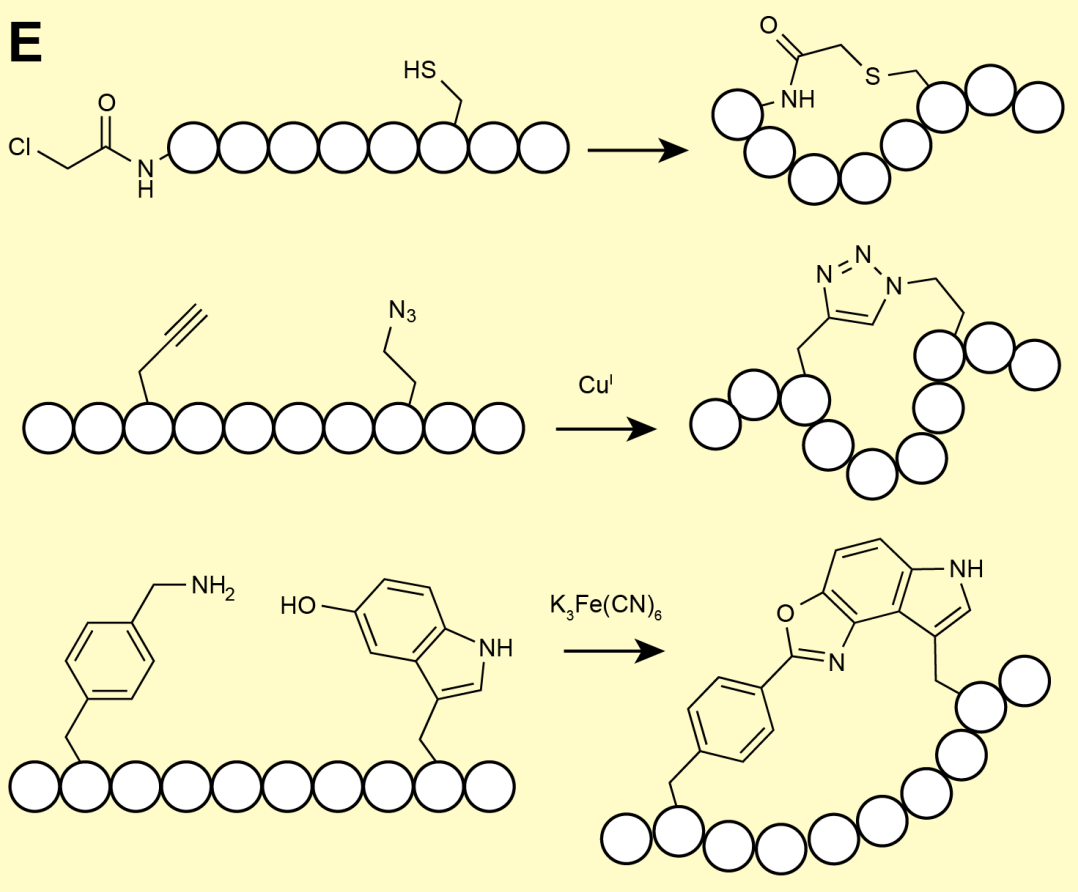


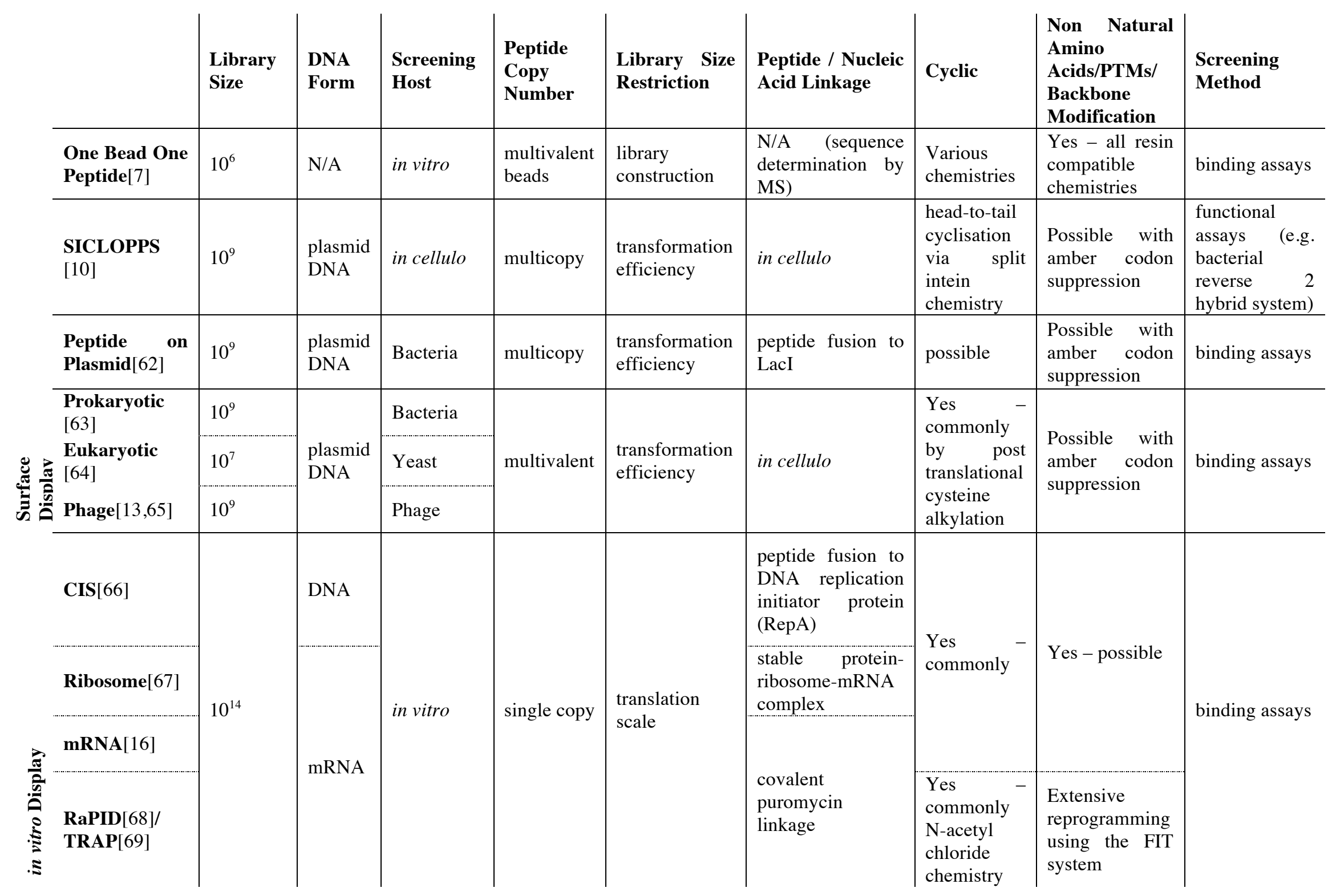


